\title{
Los cementos portland con adiciones y los cementos compuestos
}

ALBERTO VIRELLA BLODA, Ingeniero Químico

\section{EL PLIEGO DE 1975 Y ALGUNOS COMENTARIOS}

Al poco tiempo de haberse publicado en el "Boletín Oficial del Estado" el "Pliego de Prescripciones Técnicas Generales para la Recepción de Cementos", de 23 de mayo de 1975, aparecieron en las páginas de la veterana revista "CEMENTO HORMIGON" unos comentarios que reflejaban nuestro particular enfoque de algunos conceptos contenidos en tan importante Decreto (44).

Dichos comentarios merecieron una amable réplica — quizá mejor fuera decir unas aclaraciones- por parte de mi buen amigo el Dr. D. JOSE CALLEJA CARRETE, publicadas asimismo en la citada revista (5).

No entra en mis propósitos usar del derecho de "contrarréplica" ni mucho menos polemizar sobre temas expuestos por el Dr. CALLEJA con el alto nivel científico que lo caracteriza, sino, tan sólo, desarrollar un párrafo que creo del mayor interés y que, por lo mismo, caló muy hondo en mi ánimo. El párrafo es el siguiente:

"Al tratar de las adiciones activas y de las inertes el Sr. VIRELLA califica de dudoso el umbral de separación de unas y otras - queremos entender que lo que considera dudosa es la existencia de dicho umbral y, por lo tanto, también la justificación para establecerlo-. Y añade que las adiciones "poco activas" distan "mucho" de ser inertes.

En efecto, si son activas, aunque poco, no son "totalmente inertes"; son eso: poco activas. Pero la importancia de la idea del Sr. VIRELLA se cree que reside en lo que parece que guarda "in pectore", a saber: que no se puede hablar - si no es excepcionalmente- de adiciones inertes, porque la mayor parte de las adiciones — sin calificación apriorísticason activas en algún aspecto determinado y en una cierta medida. Y, si esto es así -él menciona que está científicamente demostrado-, cabe preguntar y tratar de establecer en qué aspecto.(s) y medida(s) - y en qué circunstancias y en qué signo- es activa una adición dada. Problema éste de interés extraordinario, cuya resolución exige, en todo caso, un gran volumen de trabajo experimental".

Digamos, en primer lugar, que son muchas las cosas que tiene que guardar "in pectore" quien se halla, como me hallé durante más de cuarenta años, al servicio de la empresa privada. Por un anticuado y mal entendido concepto de "secretos de fabricación" tuve siempre que usar de las mayores cautelas para no incurrir en "inconfidencias" que pudieran ocasionar hipotéticos quebrantos. 
$\mathrm{Y}$, sin embargo, creo que el tema que hizo resaltar el Dr. CALLEJA es de un indudable interés general, mereciendo por ello ser tratado sincera y objetivamente, sin ánimo de perjudicar ni siquiera molestar a los dignos y probos fabricantes de cementos con adiciones.

\section{LOS CEMENTOS CON ADICIONES}

Si se nos permite dar una breve ojeada a la historia de los cementos tropezaremos con un viejo preconcepto que nos viene de la confusa patente de Joseph Aspdin, inventor, en 1824, del material que llamó Cemento Portland. Durante mucho tiempo se entendió que dicho cemento debía consistir en el producto molido del material salido de los hornos, separados los incocidos, y sin cualquier tipo de adición. E. CANDLOT, en 1891 (6) usa las palabras fraude y falsificación al referirse a la introdución de materias extrañas, en especial escorias de alto horno, al cemento portland.

Incluye el primer Pliego de Condiciones francés, que define al cemento portland como el producto de la molienda de rocas escorificadas, obtenidas por cocción, hasta reblandecimiento, de una mezcla íntima de carbonato de cal y de arcilla, rigurosamente dosificada, química y físicamente homogénea en todas sus partes. No admitía, siquiera, la adición de yeso, hasta el punto de que cualquier cemento que contuviera más de $1 \%$ de ácido sulfúrico o sulfuros en proporción dosable, debía ser rechazado.

La adición de yeso vino después, según Blount (3) como consecuencia de la introducción de los hornos rotativos y la consiguiente observación de perturbaciones en el fraguado. "El remedio natural fue añadir anhídrido sulfúrico en una u otra forma al cemento después de la moltura". Esta práctica fue consagrada por el uso y se incorporó al texto de los distintos "Pliegos de Condiciones", así, el "Pliego de Condiciones Generales para la Recepción de los Cementos Portland Artificiales en los Servicios de Obras Públicas", publicado de Real Orden en 27 de mayo de 1919, aclaraba: “... sin que las adiciones después de la cochura excedan del $3 \%$ en peso".

Evidentemente y durante un gran número de años, el cemento portland consistía en el producto de la molienda exclusiva de clínker con la sola adición de una pequeña cantidad de yeso, considerada necesaria para la regulación del fraguado. Cualquier otra adición se consideraba como una adulteración del material. Un ingeniero español, D. Ignacio Vizcaíno y Cucarella, en los albores de la industria nacional del cemento portland, se expresaba según sigue (5):

"Falsificación del producto. El yeso en cantidad menor del $2 \%$ tiene por objeto retardar el fraguado, mejora el cemento y aumenta su resistencia; en cantidad mayor produce entumecimientos peligrosos y debe considerarse como una falsificación. También se agregan al cemento escorias de altos hornos, calizas, pizarras, cenizas, arenas, restos de materias cerámicas, cemento "laitier"; todas estas substancias disminuyen la resistencia notablemente, y ninguna fábrica formal y que estime su crédito estropea su producto y aminora su valor técnico por obtener mayores rendimientos".

Meade, en 1911 (22) citaba, entre las adulteraciones más frecuentes en América, las adiciones de cemento natural, material crudo, caliza y escorias y, entre los métodos más simples para poner de manifiesto dichas adiciones las determinaciones del peso específico real, la pérdida al fuego y el residuo insoluble. Parámetros que, por lo visto, no han perdido su vigencia con el paso del tiempo, según se puede ver en la tabla que se adjunta: 
T A B L A I

Pliegos de condiciones para el cemento portland promulgados en España

\begin{tabular}{|c|c|c|c|c|c|}
\hline Año & Adición tolerada & Peso específico & Pérdida al fuego & Insol. & $\mathrm{SO}_{3}$ \\
\hline 1903 & - & 3,05 & 6,0 & - & 1,5 \\
\hline 1919 & 1,5 & 3,05 & 4,0 & 1,5 & 2,5 \\
\hline 1930 & 3,0 & 3,05 & 4,0 & 1,5 & 2,5 \\
\hline 1959 (1) & 10,0 & 3,0 & 3,0 & 1,5 & 4,0 \\
\hline $1964\left(c^{i}\right)$ & 10,0 & 3,0 & 4,0 & 3,0 & 4,0 \\
\hline 1975 (3) & - & - & 3,5 & 2,5 & 4,5 \\
\hline 1975 (4) & - & - & 4,0 & 4,0 & 4,0 \\
\hline
\end{tabular}

En (1) se prescribía textualmente: "Eventualmente, puede darse la denominación comercial de cemento portland a aquellos que, además de los componentes principales, clínker y piedra de yeso, contengan otras adiciones no nocivas en proporción inferior al $10 \%$, con objeto de mejorar algunas de las cualidades de los conglomerantes o de los morteros y hormigones con ellos fabricados, siempre que los cementos resultantes cumplan todas las condiciones químicas, químicas y mecánicas que se especifican para el portland en el presente Pliego". Dicha cláusula se repetía textualmente en (2).

En el Pliego de 1975 se definen dos materiales distintos: Los Cementos Portland (3) y los Cementos Portland con Adiciones Activas (4). Para los cementos (3) se omite cualquier referencia a porcentajes de adiciones, pero se establecen (en especial para la calidad P-450) unos límites tan estrictos en la pérdida al fuego y en el residuo insoluble que excluyen, de antemano, la simple hipótesis de determinadas adiciones.

Para los cementos (4), en cambio, todos son facilidades. Se aumenta el límite de la pérdida al fuego, el residuo insoluble se establece en $4 \%$, pero elevado a $8 \%$ si se trata de adición de puzolana y sin límite alguno cuando se emplean cenizas volantes. El peso específico real, que en (1) y (2) se había rebajado de 3,05 a $3,0 \mathrm{~g} / \mathrm{cm}^{3}$, desaparece de la tabla de valores en (4) y (5). Aparentemente, es una facilidad que se da a las dos calidades de cemento portland, pero que, en realidad, tan sólo beneficia a los que contengan "adiciones activas".

\section{ADICIONES NO NOCIVAS Y ADICIONES ACTIVAS}

No se trata de jugar con las palabras, pero es notable ver la diferencia que existe entre una adición no nociva y una adición hidráulicamente activa. Porque una adición inactiva puede, sin duda, no ser nociva. A lo más, rebajará la resistencia mecánica, pero si ésta se mantiene dentro de los límites establecidos no habrá nada a reclamar; en cambio una adición hidráulicamente activa puede ser beneficiosa o nociva, principalmente si nos referimos al problema de la durabilidad de los hormigones. Y si bien podríamos citar algunos ejemplos, diremos que no es ésta la motivación que nos mueve en este momento.

Parangonando al Dr. CALLEJA cabría, sin embargo, preguntar: "en qué aspecto(s) y medida(s) - y en qué circunstancias y con qué signo- es nociva una adición dada. Problema éste de interés extraordinario, cuya resolución exige, en todo caso, un gran volumen de trabajo experimental". 
Así como anteriores Pliegos (1) y (2) dejaban el concepto de adiciones no nocivas en el más absoluto indeterminismo, en (4) se especifican muy bien lo que son y cuáles son las adiciones hidráulicamente activas: materiales que poseen propiedades hidráulicas latentes, como algunas escorias siderúrgicas, o que son capaces de fijar la cal, como las puzolanas, y, por extensión, otros productos naturales o artificiales que tienen propiedades análogas, tales como la tierra de diatomeas, las arcillas activadas y las cenizas volantes.

También se definen las adiciones inertes (suponemos que inertes se sinonimiza con no activas) y que deben entrar solamente en los cementos compuestos. Textualmente: "Se entiende por adiciones inertes los materiales que, sin perturbar el fraguado, el endurecimiento o la estabilidad de volumen, introduzcan alguna mejora en cuanto a adherencia, plasticidad, blancura o rendimiento de las pastas, morteros u hormigones, o cualquier otra característica que pueda afectar favorablemente a éstos. Estas adiciones se utilizarán exclusivamente como componentes del cemento compuesto" (27).

Se reconoce en dicho texto que las adiciones designadas por inertes no deben (y de hecho cumplen con lo dispuesto) causar perturbaciones en el fraguado, endurecimiento y estabilidad de volumen. En una palabra, no deben ser nocivas, y no lo son. Pero lo lamentable del caso reside en lo especificado para los cementos compuestos: "Los cementos compuestos son de una sola clase y categoría":

Denominación

Cemento compuesto 200
Designación

C-200

Cabe formularse la pregunta de si no es posible producir cementos compuestos que presenten a los 7 días resistencias a la rotura por compresión superiores a los $100 \mathrm{kp} / \mathrm{cm}^{2}$ y a los 28 días mayores que $200 \mathrm{kp} / \mathrm{cm}^{2}$. La respuesta es afirmativa, puesto que existen y cumplen perfectamente lo establecido para el P-350 y el P-450 y no dudamos que los fabricantes sabrán obtener cementos compuestos cumpliendo los requisitos del P-550. Serán, desde luego, unos cementos no reconocidos por el Pliego, podríamos decir que "al margen de la ley" y, cuando esto sucede, se acude a toda clase de eufemismos y tapujos para introducirse, subrepticiamente, dentro de lo prescrito en los textos legales. De ahí la huera discusión sobre conservación de muestras, carbonatación de los cementos y la diferencia entre el contenido total de materias inertes y el contenido de materias incorporadas. Si la ley fuera seguida de un deseable "Apéndice", lo único que se discutiría es el fraguado, endurecimiento, estabilidad de volumen y resistencia mecánica de los cementos compuestos. Con lo cual habríamos ganado algo en efectividad y en sinceridad, conceptos a todas luces beneficiosos.

\section{TOPOQUIMICA DE LAS ADICIONES}

$\mathrm{Si}$, después de las debidas reducciones, situamos las principales adiciones a los cementos, en el sistema ternario $\mathrm{SiO}_{2}-\mathrm{Al}_{2} \mathrm{O}_{3}-\mathrm{CaO}$ (fig. 1) podremos establecer cinco zonas:

1) Escorias siderúrgicas.

2) Cenizas volantes.

3) Puzolanas naturales.

4) Arena.

5) Cal (o caliza). 
De la bibliografía consultada se obtuvieron las composiciones siguientes:

TAB L A II

Composición ternaria de las adiciones "activas"

\begin{tabular}{clccc}
\hline & & $(1)$ & $(2)$ & $(3)$ \\
\hline \multirow{2}{*}{$\mathrm{SiO}_{2} \%$} & Máximo & 44,2 & 71,1 & 78,5 \\
& Media & 44,6 & 54,2 & 67,5 \\
\cline { 2 - 5 } & Mínimo & 29,0 & 33,6 & 39,3 \\
$\mathrm{R}_{2} \mathrm{O}_{3} \%$ & Máximo & 35,1 & 76,9 & 59,6 \\
& Media & 17,7 & 40,5 & 27,8 \\
\cline { 2 - 5 } & Mínimo & 5,7 & 24,2 & 17,4 \\
& Máximo & 58,5 & 43,6 & 12,0 \\
& Media & 37,7 & 5,3 & 4,7 \\
\cline { 2 - 5 } & Mínimo & 29,5 & 1,0 & 1,0 \\
\hline
\end{tabular}

Las zonas 4) y 5) se sitúan, obviamente, en los correspondientes vértices del diagrama.

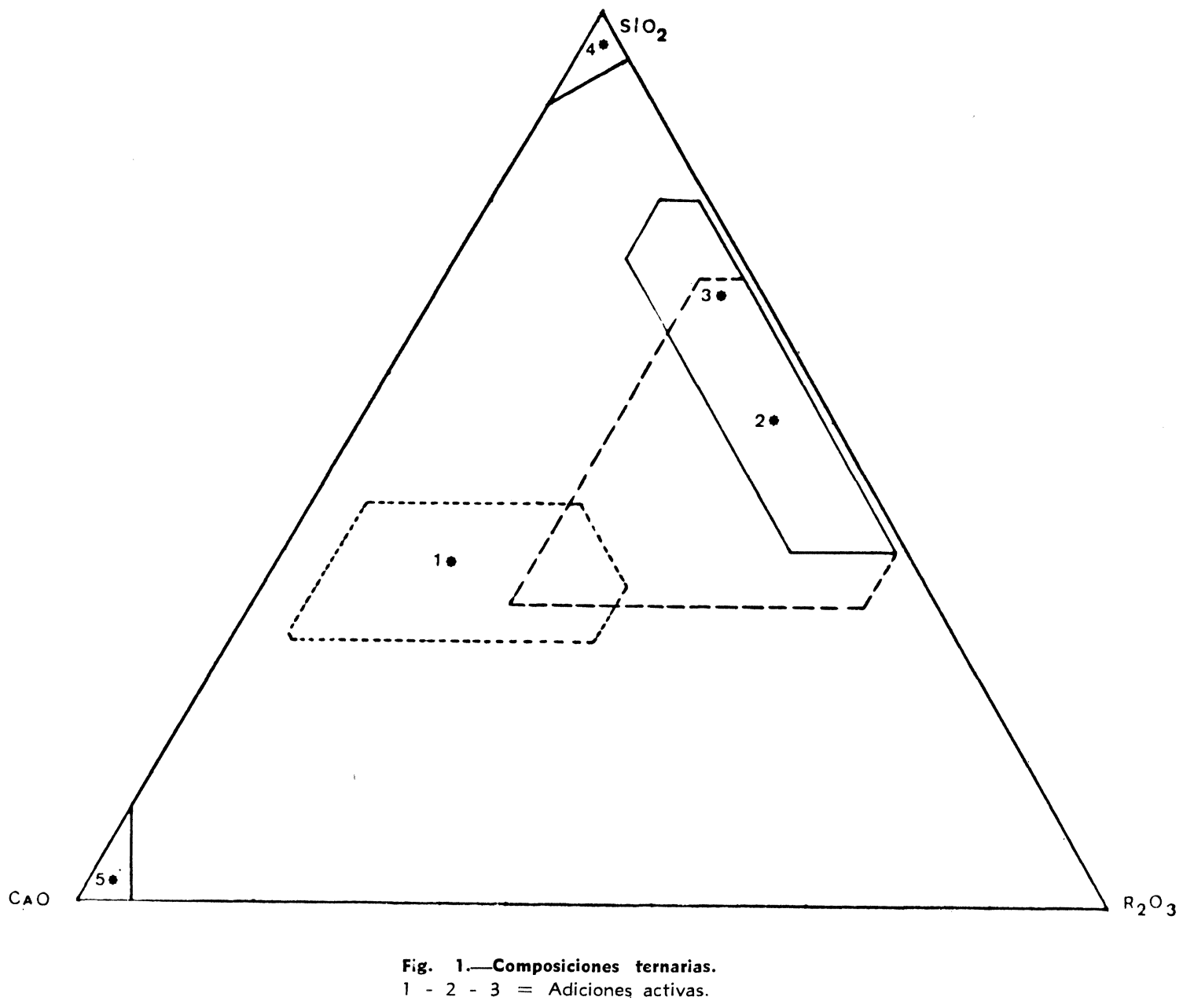


Recordando su origen, las zonas 1) y 2) corresponden a subproductos industriales generados a temperaturas elevadas, con grandes posibilidades de que sus estructuras cristalinas se presenten desordenadas y poco estables, con una acusada inestabilidad por la presencia activa de átomos de elementos extraños al sistema y de difícil acomodación en la red estructural.

La zona 3), correspondiente a puzolanas naturales, presentan una gran abundancia de sílice, con el complejo $\mathrm{SiO}_{4}$ acomodado en estructuras que no son las más estables. Ello se atribuye a la procedencia eruptiva de las puzolanas naturales, o a transformaciones biológicas, como en el caso de la tierra de diatomeas. En general, estos materiales deben activarse por medio de un secado, lo que en cierto modo equivale a restablecer el desorden donde la edad y la intemperie habían establecido un aparente orden.

La arena natural ocupa la zona 4), y la cal, o mejor dicho, la calcita equivalente, la zona 5). De la estabilidad natural de la arena cuarzosa y de la calcita dan pruebas fehacientes los grandes depósitos que, de uno y otro, existen en nuestra litosfera con una antigüedad geológica incalculable. Ello parece dar razón a la divisoria marcada entre adiciones activas y adiciones inertes, como cosa bien clara y definida, convirtiendo toda discusión en un puro bizantinismo.

\section{ADICIONES DE ARENA}

Que la arena cuarzosa, en su estado natural y en las condiciones normales de presión y de temperatura, es poco menos que inerte parece estar fuera de dudas. Sin embargo, se sabe que antiguos morteros de cal y arena, debidamente examinados, presentan claras señales de combinación química de ambos componentes en la superficie de los granos cuarzosos. Claro está que la velocidad de reacción es tan pequeña que no merece tener en cuenta dicho fenómeno.

Hay, sin embargo, formas de activar la arena. La primera es por fragmentación mecánica. La finura desarrolla superficies de contacto, y Jander ha comprobado que la velocidad de reacción es inversamente proporcional al cuadrado del radio medio del gránulo (13). Ya Michaelis comprobó que, reduciendo el cuarzo a un polvo impalpable, mediante una molienda prolongada, se vuelve tan activo como para convertirse en ácido silícico hidratado coloidal por la simple hervura con agua (23). Para Lea (17) no existe una clara línea de demarcación entre sílice soluble e insoluble, creyendo que la reactividad se debe principalmente a la gran superficie que se presenta a la acción del reactivo.

Los trabajos de H. F. W. TAYLOR y sus colaboradores, iniciados en 1948 (33), demostraron la posibilidad de formarse dos tipos de silicatos cálcicos hidratados, a temperaturas normales, partiendo de suspensiones acuosas de cal y sílice. Los dos silicatos que se forman son:

$\mathrm{SCH}$ (I) Variedad pobre de cal, de composición entre $\mathrm{SCH}_{\mathrm{x}}-\mathrm{S}_{2} \mathrm{C}_{3} \mathrm{H}_{\mathrm{y}}$.

$\mathrm{SCH}$ (II) Variedad rica de cal, cuya composición es $\mathrm{SC}_{2} \mathrm{H}_{\mathrm{x}}$.

O sea, $\mathrm{SCH}$ (I) pertenecerá al grupo de la tobermorita y $\mathrm{SCH}$ (II) será afín a la afwillita (35). Estas experiencias, de reacciones entre la sílice y la cal a la temperatura ambiente, ya las había realizado CHASSEVENT antes de 1936 (10) con análogos resultados.

A temperaturas y presiones más elevadas la reacción se activa enormemente, lo cual dio nacimiento a la industria de los aglomerados sílico-calcáreos autoclavados, patentada por Van Derburg en 1866 y mejorada por la patente de Michaelis en 1880 (1). No nos exten- 
deremos sobre una industria que, en este caso, no afecta directamente al problema de los cementos, pero sí que podemos decir que, en el seno de una pasta de cemento en curso de fraguado, cuando se desarrollan las temperaturas y presiones propias del fenómeno, un sistema muy disperso de partículas silíceas puede adquirir una actividad no desdeñable.

INDICE DE RESISTENCIA (\%)

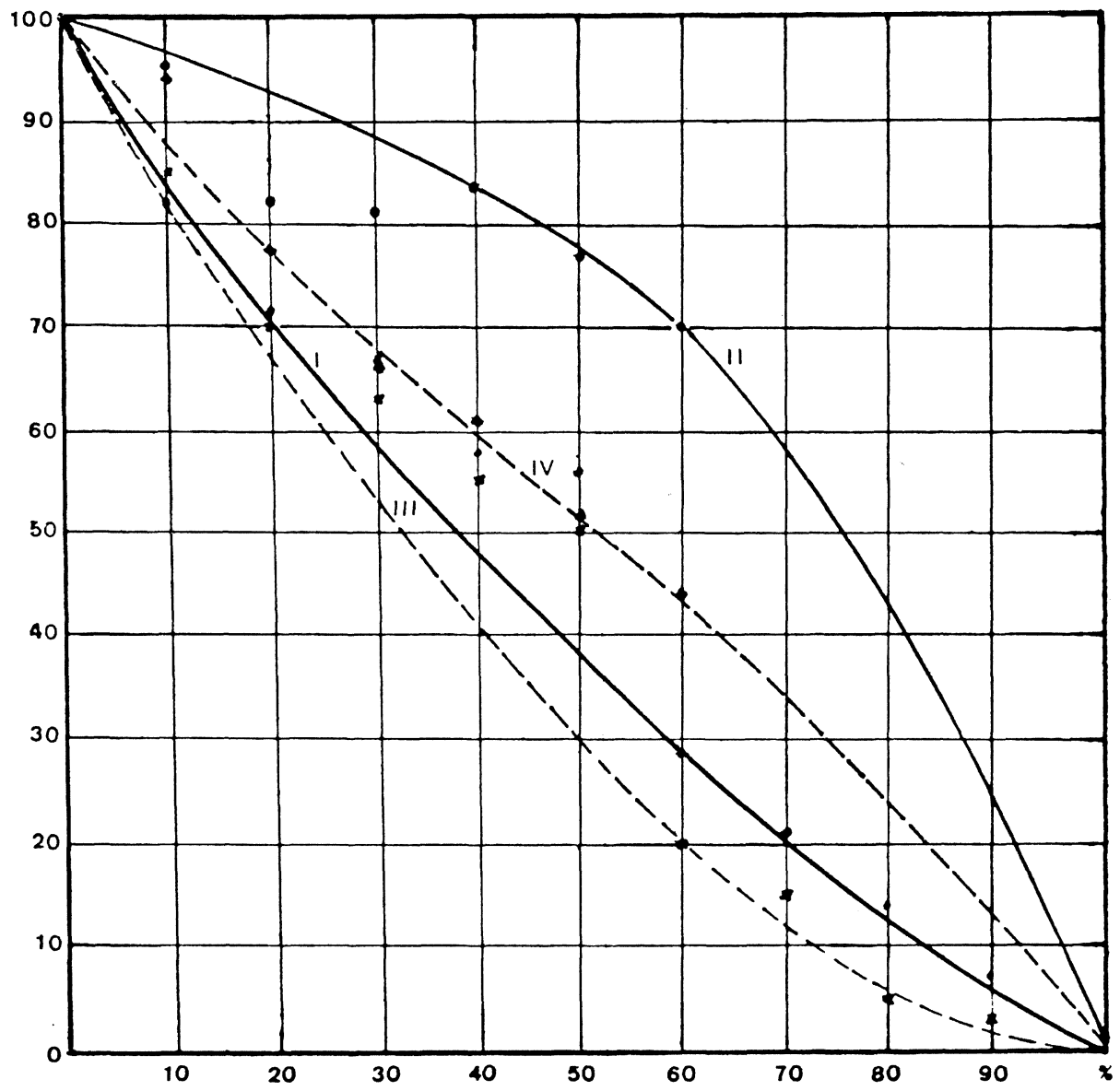

PORCENTAJE DE ADICION

Fig. 2.-Resistencias a la compresión de cementos con adiciones.

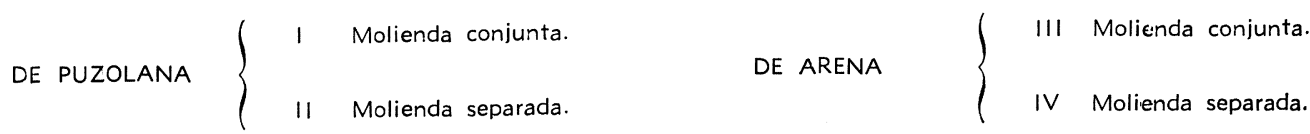

La mezcla de arena al cemento ("sand-cement") se ha realizado en varios países y épocas. Aunque a la arena no se le reconocen propiedades puzolánicas, lo cierto es que el "sandcement" se aplicó en los Estados Unidos, a principios de siglo, en la construcción de algunas presas, y con pleno éxito. En épocas de carestía, como la provocada por la guerra 1939-1945, se mezcló arena al clínker de cemento portland como medida de índole económica (17).

Finalmente, también se emplea la mezcla de arena molida en algunos cementos de albañilería (Masonry Cements), siempre que a la mezcla se le añada un agente aireante con el fin de conseguir una docilidad análoga a la de los morteros de cal y arena (18). 
Como veremos más adelante, el buen resultado de la adición de arena es función de la técnología aplicada. Una mala tecnología puede conducir a resultados muy mediocres. Por nuestra parte podemos presentar los resultados de unos ensayos realizados en 1959, con mezclas de clínker, con arena o puzolana. La mezcla se hizo de dos formas: moliendo conjuntamente, o por separado. Los resultados se resumen en la siguiente tabla y en la figura 2.

T A B L A III

Indices de resistencias a la rotura por compresión por el efecto de adiciones

\begin{tabular}{ccccc}
\hline $\begin{array}{c}\text { FORMA DE MOLIENDA } \\
\text { Adición } \\
(\%)\end{array}$ & $\begin{array}{c}\text { CONJUNTA } \\
\text { Puzolana } \\
(\%)\end{array}$ & $\begin{array}{c}\text { SEPARADA } \\
\text { Puzolana } \\
(\%)\end{array}$ & $\begin{array}{c}\text { CONIUNTA } \\
\text { Arena } \\
(\%)\end{array}$ & $\begin{array}{c}\text { SEPARADA } \\
\text { Arena } \\
(\%)\end{array}$ \\
\hline 0 & 100 & 100 & 100 & 100 \\
10 & 82 & 95 & 83 & 94 \\
20 & 71 & 82 & 70 & 77 \\
30 & 67 & 81 & 63 & 67 \\
40 & 58 & 84 & 55 & 61 \\
50 & 56 & 77 & 50 & 51 \\
40 & 29 & 70 & 20 & 44 \\
30 & 21 & - & 13 & - \\
10 & 14 & - & 5 & - \\
\hline
\end{tabular}

La puzolana empleada procedía de Cabo Verde y la arena procedía de landas holocénicas, con un contenido en $\mathrm{SiO}_{2}$ del orden del $95 \%$. Se nota, desde luego, una superioridad de la acción puzolánica, pero la arena, finamente molida por separado del clínker, dista de poder considerarse como absolutamente inactiva.

\section{ADICIONES DE CALIZA}

Las adiciones de caliza en algunos tipos de cemento las podemos considerar clásicas. Sin embargo, el conocimiento de su posible actividad químico-física es bastante reciente.

La primera noción a que, a este respecto, se hizo referencia fue la de epitaxia, entendiendo por tal el fenómeno consistente en el crecimiento orientado de dos especies cristalinas diferentes, fenómeno que se da cuando existen ciertas analogías en la forma y dimensiones de los retículos cristalinos de ambas sustancias. La existencia de una ligazón epitáxica entre la pasta de cemento y los agregados calcáreos fue defendida por Vie (38), Farran (11) y otros.

En uno de dichos trabajos leemos: "Estudiando comparativamente las estructuras de la portlandita y de la calcita se observa la existencia de una red espacial común. Se constata, efectivamente, por otra parte, que los cristales de calcita que se forman por consecuencia de la carbonatación superficial de la cal hidratada están, generalmente, orientados por éstos últimos; nos hallamos, sin ambigüedad posible, en presencia de una epigenia epitáxica. Por lo tanto, es legítimo pensar que, por su parte, los cristales de portlandita pueden ser orientados por los de la calcita cuando se forman en su contacto". 
En otro sitio ya ponderamos las cualidades de los áridos calcáreos, que nos resistíamos a que se consideraran como inertes (37). Rockwood (30) citó el caso del noruego Arne Daniels, que registró un producto, bajo el nombre de "Activit", el cual, mezclado al cemento portland, producía un hormigón provisto de cualidades envidiables. El producto no era más que una calcita "con propiedades especiales", finamente molida, preguntándose Rockwood si la calcita pulverizada era meramente un adulterante del cemento.

Posteriormente, Spohn y Lieber comprobaron que la adición de $\mathrm{CO}_{3} \mathrm{Ca}$ proporciona una mayor resistencia a las probetas de ensayos normales y que, ejerciendo dicha adición cierta influencia sobre los tiempos de fraguado, podía substituir parcialmente al yeso en su papel de regulador. En el curso de las reacciones de hidratación, sea en pasta o sea en suspensión acuosa, el $\mathrm{CO}_{3} \mathrm{Ca}$ reacciona con el $\mathrm{AC}_{3}$ y el $\mathrm{AFC}_{4}$ para formar el compuesto $\mathrm{Al}_{2} \mathrm{O}_{3} \cdot 3 \mathrm{CaO} \cdot \mathrm{CO}_{3} \mathrm{Ca} \cdot 10 \mathrm{H}_{2} \mathrm{O}$.

En el Simpoisum de Tokio, Chatterji (9) proponía un mecanismo por el cual el $\mathrm{AC}_{3} \mathrm{H}_{13}$ se convirtiese en un compuesto más estable, capaz de cambiarse en ettringita con poca expansión, pareciendo ser que el antecitado carbo-aluminato cumple estas exigencias, por lo que es de esperar que, con la adición al cemento de $\mathrm{CO}_{3} \mathrm{Ca}$ muy finamente pulverizado, resulte un material que proporcione muy poca expansión cuando se exponga a la acción de soluciones sulfatadas, y concluye: "Este corolario del mecanismo propuesto se ha comprobado recientemente".

Parece ser, pues, que la adición de calcita finamente molida es beneficiosa para el cemento y que, incluso, se puede observar una cierta elevación de las resistencias mecánicas desde que se opere dentro de unos límites prudenciales (31) y no se empleen calizas de composición dudosa. Así, se ha señalado una actividad negativa, o sea, perjudicial, para las calizas margosas (12) y muy particularmente para las calizas dolomíticas, muy sensibles a la reacción de los álcalis, según Hadley y colaboradores.

Los resultados obtenidos en el laboratorio con adiciones de caliza, fueron los siguientes, (expresados gráficamente en la figura 3 ):

T A в L A IV

Indices de resistencias a la compresión por el efecto de la adición de caliza

\begin{tabular}{cccc}
\hline $\begin{array}{c}\text { FORMA DE MOLIENDA } \\
\text { Adición } \\
(\%)\end{array}$ & $\begin{array}{c}\text { CONJUNTA } \\
\text { Caliza } \\
(\%)\end{array}$ & $\begin{array}{c}\text { SEPARADA } \\
\text { Caliza } \\
(\%)\end{array}$ & $\begin{array}{c}\text { PERDIDA AL FUECO } \\
(\%)\end{array}$ \\
\hline 0 & 100 & 100 & 0,96 \\
5 & - & 105 & 2,98 \\
10 & 54 & 99 & 4,56 \\
15 & -- & 94 & 7,68 \\
20 & 47 & 88 & 8,68 \\
25 & - & 80 & 11,28 \\
30 & 34 & - & 12,59 \\
40 & 10 & - & 16,18 \\
60 & 8 & - & 25,79 \\
80 & 3 & - & 33,14 \\
100 & - & & 43,42 \\
\hline
\end{tabular}


Puesto que, en determinadas condiciones de molienda, con $20 \%$ de adición la reducción de resistencia tan sólo alcanzó $12 \%$ con respecto al cemento sin mezcla, se comprende la posibilidad de obtener muy altas resistencias, como de hecho se obtienen en los cementos con adiciones.

INDICE DE RESISTENCIA (\%)

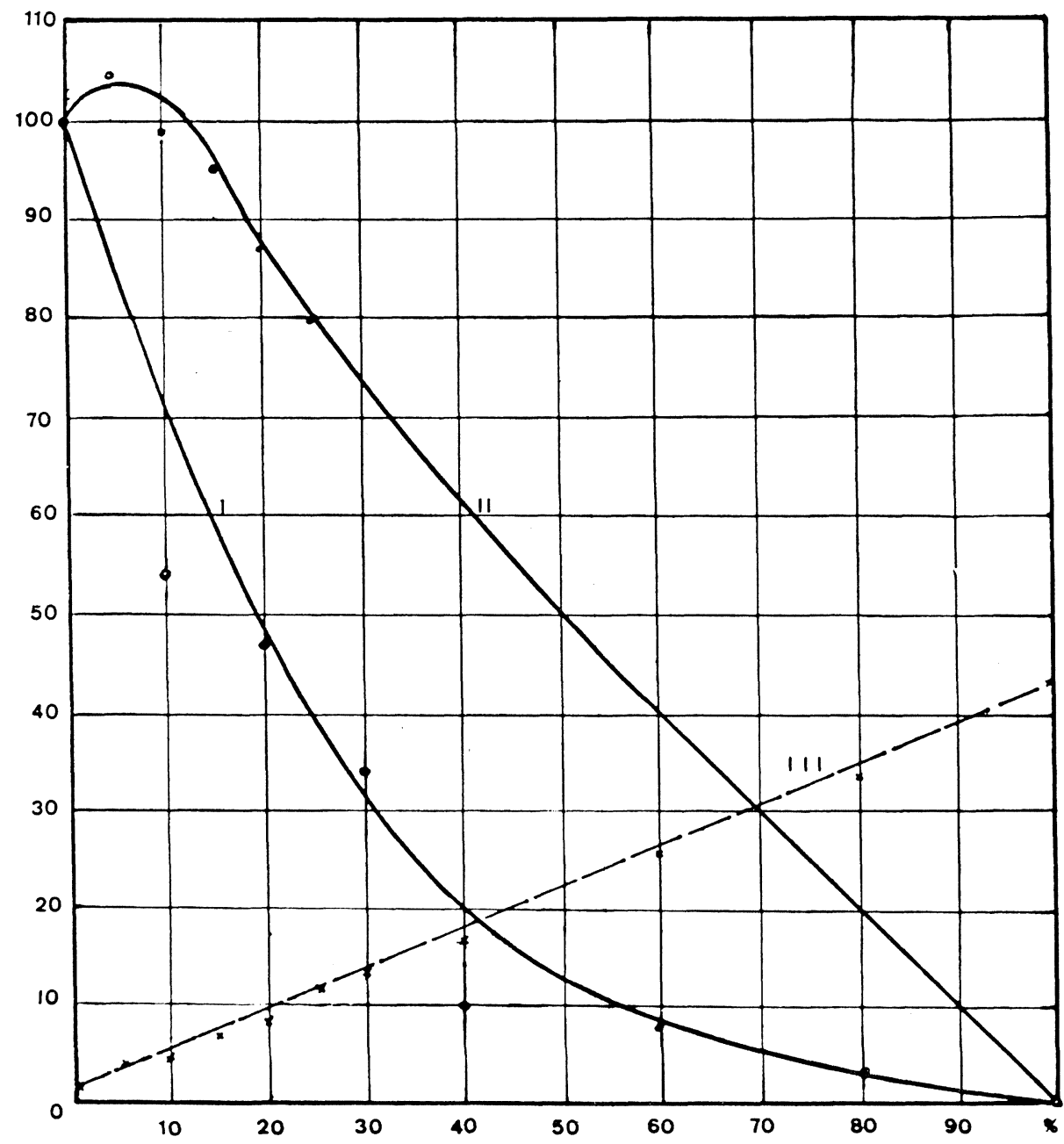

PORCENTAJE DE ADICICN

Fig. 3.-Resistencias a la compresión de cementos con adiciones de caliza.

I Molienda conjunta.

11 Molienda separada.

III Pérdida al fuego (\%).

\section{\%. LA MOLIENDA DE LOS CEMENTOS CON ADICIONES}

Ya hicimos resaltar en los anteriores ejemplos que la calidad de los cementos con adiciones depende mucho de la técnica empleada en la molienda. Se sabe que la llamada movilidad o aptitud para la molienda (26) es una propiedad característica de cada cuerpo. En otro lugar dimos algunos de los indices de trabajo determinados de acuerdo con la tercera teoría de BOND (42). Son, entre ellos, los siguientes: 
TABLA $\mathrm{V}$

\begin{tabular}{lcc}
\multicolumn{1}{c}{ Materiales } & Peso específico real & Indice de trabajo \\
\hline Yeso & 2,69 & 6,73 \\
Caliza blanda & 2,66 & 6,73 \\
Esconias de alto horno & 3,88 & 9,97 \\
Caliza dura & 2,64 & 12,54 \\
Clínker de cemento portland & 3,15 & 13,45 \\
Arena silícea & 2,67 & 14,10 \\
\hline
\end{tabular}

Quiere esto decir que, si sometemos conjuntamente a una operación de molienda en circuito abierto dos materiales con diferente índice de trabajo, se molerá más fácilmente aquélla que lo tenga más bajo; o sea, en los finos aparecerá un mayor porcentaje de las materias de baja movilidad y en los gruesos sucederá lo contrario. Así, por ejemplo, si se trata de una mezcla de clínker y calcita, en los finos predominará la calcita y en los residuos el clínker.

En una mezcla de clínker y arena sucederá lo contrario. Las consecuencias serán desfavorables en ambos casos. En el primero, el clínker quedará deficientemente molido y, por ello, desarrollará muy poco las resistencias iniciales. En el segundo, la adición de arena quedará muy gruesa $\mathrm{y}$, desde luego, poco reactiva.

En la molienda por circuito cerrado estas diferencias serán menos notorias: los materiales con alto índice de trabajo permanecerán más tiempo en el circuito $\mathrm{y}$, en última instancia, puesto que la separación se efectúa por pesos de partículas, los materiales blandos y de poca densidad se separarán del circuito con mayores tamaños que los materiales densos y duros.

Todas estas particularidades de la molienda ison bien conocidas desde hace tiempo por parte de los fabricantes de cementos con adiciones y, muy especialmente, por los de cementos de escorias o de puzolanas. Palomar Llovet (25) citó un nuevo tipo de cemento, i.deado en el Japón, por Toru Mori, a base de dos partes de escorias siderúrgicas y una parte de clínker blanco, mezclados después de un molido por separado de ambos productos; Ferrari, en un artículo que glosamos póstumamente (41) nos decía: "Industrialmente se preparan (los cementos ferri-puzolánicos) por homogeneización del clínker Ferrari adicionado con el yeso necesario y con la puzolana, molidos por separado (esta práctica que hace tiempo vengo recomendando para la producción más rentable de los cementos puzolánicos, solamente en Italia ha sido tomada en consideración hoy día)". Pero no se trata, únicamente, de la mezcla clínker-puzolana; D. A. WADIA, en 1952, proponía la molienda separada del clínker y del yeso para dar a cada material la finura más conveniente y evitar los fenómenos de falso fraguado (46).

Más recientemente, en el Simposium de Tokio, Niko Stutterheim, de Pretoria (Africa del Sur), proponía la molienda separada para los cementos de escorias. "Unicamente por este proceso puede asegurarse que la finura de la escoria es una variable controlada" (32). Kaiser, manifestando que las propiedades mecánicas de los cementos de escorias con una distribución granulométrica muy cerrada excedían a las de los cementos de igual superficie específica, pero con una gran dispersión en su distribución granulométrica, consideraba que, para conseguir este fin, la molienda por separado era el método más ventajoso (14). Birthelmer participó de la misma opinión manifestando que los cementos obtenidos por molienda separada alcanzaban la misma resistencia que los cementos obtenidos por molienda conjunta, con una superficie específica mucho menor para los prime$\operatorname{ros}(2)$. 
El efecto de las adiciones de calcita ya fueron anotados por Lea, según el cual una substitución pequeña, del $2 \%$, en algunos casos puede aumentar la resistencia, probablemente por su acción de favorecer la molienda. Parece que estos efectos son muy específicos y se ha visto que la misma marga dura, cuando se emplea en la cantidad de $10 \%$ en un clínker, reduce en un 10-15\% su resistencia y, en otros casos, queda más o menos invariable. Esto puede ser debido a diferente clase de molienda (20).

Así, pues, podríamos decir que, como norma general, cuando las adiciones al clínker, aparte del yeso, entran en muy pequeña cantidad, por debajo de un $5 \%$, es recomendable la molienda conjunta, principalmente si la adición se comprueba que ejerce un efecto coadyuvante de la operación. Para adiciones mayores, los ensayos de laboratorio (figs. 2 y 3 ), la bibliografía consultada y la práctica industrial se inclinan a favor de la molienda separada.

\section{CASOS INTERESANTES DE CEMENTOS CON ADICIONES}

\subsection{Cementos de albañilería (Masonry cements)}

No aparecen discriminados en el Pliego de 1975 y, por lo tanto, deben forzosamente incluirse en los CEMENTOS COMPUESTOS, que como se especifica "son de una sola clase y categoría".

Según la definición dada por CEMBUREAU en 1958, "son cementos hidráulicos, basados en el cemento portland, conteniendo uno o más materiales de naturaleza relativamente inerte, con el propósito de proporcionarles unas propiedades especiales, tales como la plasticidad y la retención de agua, que son de interés en los trabajos de albañilería" (8). En dicho texto se extractan las normas que entonces vigorizaban en Estados Unidos de América, Canadá, Francia, Alemania Occidental, Polonia, Unión Soviética y Yugoslavia.

En muchos países ni siquiera se establecen límites para las adiciones. En U.S.A. se establece especialmente que el cemento de albañilería no debe teñir la piedra caliza (nonstaining). En Francia se pueden agregar hasta $35 \%$ de materias inertes o $50 \%$ de escorias siderúrgicas. También se permite la adición de puzolanas. En Alemania se dice que, ordinariamente, contienen $30 \%$ de clínker de cemento portland, cal grasa o cal dolomítica. La unión Soviética especifica que deben contener, por lo menos, $50 \%$ de clínker cuando se mezclan con materiales inertes y $15 \%$ en mezclas con escorias siderúrgicas.

Las prescripciones de orden químico son pocas. En ningún caso hay limitaciones para la pérdida al fuego; Francia admite hasta un $35 \%$ de residuo insoluble dando un método para el cálculo de las agregaciones cuando contienen carbonatos de calcio o de magnesio. El MgO se limita a un máximo de $5 \%$ en Polonia y Yugoslavia. En Fancia se exige un prolongado ensayo de expansión por el método Le Chatelier cuando el contenido de $\mathrm{MgO}$ es superior a $3 \%$. Estados Unidos y Canadá exigen que los álcalis solubles, expresados como $\mathrm{Na}_{2} \mathrm{O}$, no alcancen un máximo de $0,03 \%$. El máximo para el $\mathrm{SO}_{3}$ va de $3 \%$ (Francia, Polonia) a 3,5\% (Yugoslavia).

Las resistencias mecánicas que se les exigen, son, en general, bastante bajas, puesto que su empleo no está previsto para trabajos estructurales. Así, en resumen, para los países citados, se tenía: 
TABLA VI

Resistencias a la compresión exigidas a los cementos de albañilera según normas

\begin{tabular}{lccc}
\hline Pa ís & Año de la norma & \multicolumn{2}{c}{ Resistencias en $\mathbf{k p} / \mathbf{c m}^{2}$} \\
& & $\mathbf{7}$ dias días \\
\hline Canadá & 1956 & 35 & 63 \\
Francia & 1950 & & \\
CM 100-160 & & 100 & 160 \\
CM 160-250 & 160 & 250 \\
Alemania Occidental & 1943 & 75 & 150 \\
Polonia & 1951 & 80 & 150 \\
U.S.A. & 1955 & 18 & 35 \\
Tipo I & & 35 & 63 \\
Tipo I" & 1949 & & 50 \\
U.R.S.S. & & 25 & 100 \\
"50" & & 50 & 150 \\
«100" & 1954 & 100 & \\
Yugoslavia & & &
\end{tabular}

Por lo expuesto se desprende que no es la resistencia a la compresión la principal propiedad que se pide a dichos cementos, sino su plasticidad, su retención de agua, sus calidades de inalterabilidad y no fisuración, etc., propiedades bien difíciles de reunir y que exigen una compleja elaboración.

En la primera edición de la obra de Lea y Desch, se puede leer que son mezclas de cemento portland con cal hidratada, caliza pulverizada, tierra de infusorios o escorias granuladas con adición o sin ella de estearato cálcico, petróleo o arcillas muy coloidales (21). $\mathrm{Su}$ aplicación a las obras de fábrica se explica porque los morteros de cemento portland son ásperos y poco plásticos $\mathrm{y}$, aun cuando en sí son fuertes, a veces no ligan bien con los ladrillos, lo que se trató de explicar, entre otras razones, por su rápido endurecimiento al ser absorbida el agua por los ladrillos porosos. Pese a que entre la primera y la segunda adición de dicha obra transcurrieron dos fértiles décadas, en 1960 se continuaba diciendo: "Aunque se ha trabajado mucho en relación con este tipo de cemento hay todavía mucho que aprender para valorar su comportamiento y particularmente sus propiedades plásticas" (19).

Taylor, en 1964, citaba a los cementos de albañilería como muy sofisticados, describiéndolos como mezclas de cemento portland con varias substancias como caliza molida y agentes aireantes (34). Quiere esto decir que la simplista suposición de que los cementos compuestos son adulteraciones de baja calidad no es de aceptar cuando se trata de proporcionar al ligante unas propiedades muy particulares a través de una depurada tecnología.

\subsection{Cementos para pozos de petróleo (Oil-Well Cement)}

Otro de Ios cementos compuestos, que no es descrito, ni normalizado, ni fabricado (pero sí consumido) en España, es el cemento para pozos de petróleo o, si se quiere, de un modo más genérico, cemento para perforaciones profundas. Este cemento se destina para ser in- 
yectado a presión, en forma de pasta pura muy fluida, con 40-50\% de agua, que no debe exudar, manteniéndose bombeable durante por lo menos $3 \mathrm{~h}$, y pudiendo soportar, bajo tierra, presiones de hasta $210 \mathrm{kp} / \mathrm{cm}^{2}$ y temperatura de hasta $200^{\circ} \mathrm{C}$ (15).

Consisten estos cementos en una mezcla de los materiales siguientes:

a) Clínker de cemento portland resistente al yeso y de bajo calor de hidratación. Aunque el cemento resistente al yeso tiene un contenido de $\mathrm{AC}_{3}$ limitado por el Pliego de 1975 al $5 \%$ se recomienda que para los pozos de petróleo no sobrepase $3 \%$.

b) Retardadores del fraguado: Se utilizan gran variedad de ellos, como son los hidratos de carbono (almidón, azúcares, celulosas solubilizadas), así como diversos ácidos y sales de radical orgánico, muy particularmente los lignosulfonatos.

c) Fluidificantes, siendo la bentonita el más ampliamente utilizado, pero también se usan la diatomita, la tierra de infusorios, algunas puzolanas, cenizas volantes y harina de cuarzo muy finamente molida (40).

Se trata, pues, de cementos compuestos de gran valor y cuya puesta a punto exige un gran trabajo de investigación y ensayos. Si los hemos citado aquí es porque, por lo menos en una de las composiciones reseñadas en la bibliografía, se demuestra el papel activo de uno de sus componentes: la harina de cuarzo finamente molida (15):

T A в L A VII

Resistencias a la compresión, a los 30 días, de un cemento para pozos profundos

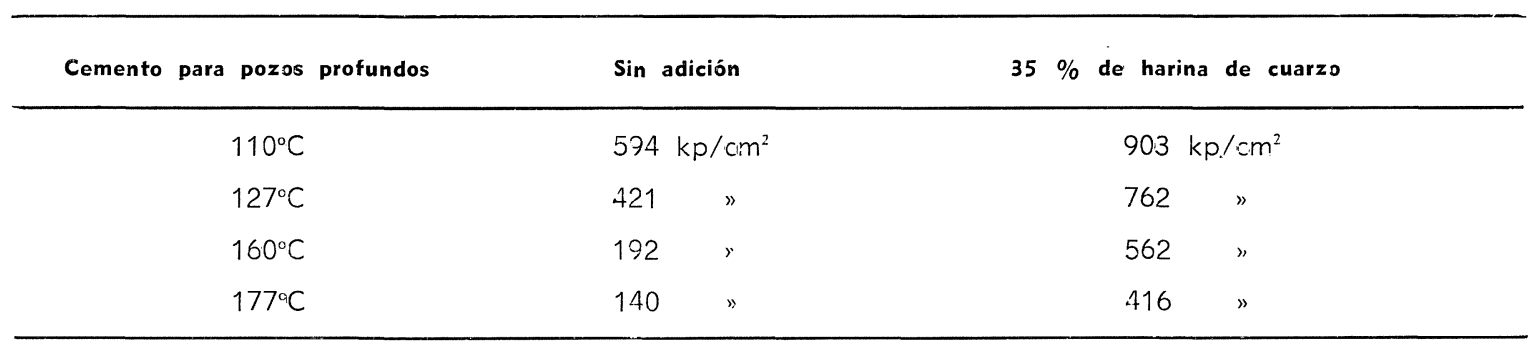

\subsection{Cementos blancos}

Los cementos blancos, con razón o sin ella, gozaron desde hace tiempo de una fama de ser cementos de adición. Una obra publicada en España, sin fecha, pero que por su contexto parece ser de los años 20, dice textualmente: "Los productos que se expenden con el nombre de cementos blancos son, en general, de clase inferior y no merecen el nombre de cemento portland. A causa de su coloración gris verdosa, es imposible transformar el cemento común en cemento blanco por medio de materias colorantes" (16). Esta idea tajante persistió durante mucho tiempo y mucho tuvieron que luchar los fabricantes de cemento blanco para desmentirla.

De todas formas, la tecnología de los cementos blancos permaneció durante años en el arcano de las ciencias ocultas y pocas eran las filtraciones de ella que salieran a la luz pública para información de las partes interesadas.

Palomar Collado, en una obra publicada en 1948 (24), sin aludir al cómo y al porqué de las posibles adiciones, daba las composiciones químicas de tres variedades de cemento blanco, que se distinguían, especialmente, por su pérdida al fuego: 


\begin{tabular}{llc}
\hline Clases de cemento & Pérdida al fuego (\%) \\
\hline Portland blanco & 1,22 \\
Blanco especial & 1,76 \\
Blanco natural & 10,06 \\
\hline
\end{tabular}

El último de los cuales (blanco natural) se describía como "dedicado especialmente a la fabricación de mosaicos hidráulicos y productos prensados en general". Se trataba, evidentemente, de un cemento con una adición de carbonto cálcico del orden de un $20 \%$. Capella Canals, en 1950, decía llanamente: "Débido a la dificultad de obtención de un tono suficientemente blanco y regular, así como a la parte económica, que obliga a mayores dispendios de fabricación, y otras razones que no hace al caso su detalle, se mezclan al clínker, durante su moltura, materiales determinados en proporción adecuada para que sus resistencias no sean desmejoradas" (7). Añade que la pérdida al fuego, en la inmensa mayoría de cementos blancos de excelente calidad, sobrepasa el máximo tolerado por las respectivas normas; citando, como ejemplos:

$$
\begin{aligned}
& \text { "Lafarge" (Francia) } \\
& \text { "Atlas" (Estados Unidos) } \\
& \text { "Griffi" (España) } \\
& \text { "Rigas" (España) }
\end{aligned}
$$

$$
\begin{aligned}
& \text { P.F. }=7,50 \% \\
& \text { P.F. }=10,50 \% \\
& \text { P.F. }=11,00 \% \\
& \text { P.F. }=18,50 \%
\end{aligned}
$$

Implícitamente, debe tratarse de unos cementos de la clase blanco natural, designación a todas luces impropia, por tratarse de cementos artificiales y que, con sobrada razón, fueron posteriormente llamados, en España, blanco para pavimentación.

En el congreso Internacional del Cemento, celebrado en Lisboa en 1960, detallamos una serie de cementos blancos diferentes del portland, o sea:

Cemento blanco natural.

Cemento blanco para pavimentación.

Cemento blanco puzolánico.

Cemento blanco de escorias.
Cementos blancos aluminosos.

Cementos blancos baríticos.

Cementos blancos oxi-salinos.

Cementos blancos de sulfato cálcico.

Circunscribiendo nuestros comentarios a los dos primeros, entendiendo por blanco natural el cemento originariamente obtenido en Francia, de la molienda de "grappiers" procedentes de la cocción de cales blancas muy hidráulicas en hornos verticales. El blanco para pavimentación procedía, en cambio, de la mezcla, durante o después de la molienda, de clínker de portland blanco con un agregado "inerte", generalmente creta, polvo de mármol o cualquier otro, que no deteriorara el color, con la finalidad de disminuir los fenómenos de retracción que tanto perjudican la cara vista de los mosaicos hidráulicos (39).

El fenómeno de la retracción en los cementos blancos había sido puesto de manifiesto por Rimathe, en 1959: "Los ensayos demostraron que el cemento blanco en pasta pura se agrieta más rápidamente que el cemento portland ordinario. La diferencia disminuye cuando se trata de mortero u hormigón blanco...".

Por otra parte, decía que los cementos por él estudiados presentaban un cierto contenido de productos inertes, o sea, "de productos añadidos por cualquier motivo al cemento, pero que no participan en el proceso de endurecimiento propiamente dicho. Los ensayos de- 
muestran que la proporción de estos productos es inferior a los límites autorizados por las normas SIA para el cemento portland (29). Se refería a las Normas Suizas SIA n. ${ }^{\circ} 115$ (1933), según las cuales:

$\begin{array}{lrr}\mathrm{SO}_{3} & \text { máx. } & 2,5 \% \\ \text { Pérdida al fuego } & \text { máx. } & 5,0 \% \\ \text { Insolubles }+\mathrm{CO}_{3} \mathrm{Ca} & \text { máx. } & 5,0 \% \\ \text { Insolubles }+ \text { yeso }+\mathrm{CO}_{3} \mathrm{Ca} & \text { máx. } & \% \\ \text { Tolerancia } & 30 & \%\end{array}$

Lo curioso es que Suiza no producía, pero si importaba, cementos blancos, y en la clase de portland blanco, y a los cementos importados les consentía una determinada agregación de $\mathrm{CO}_{3} \mathrm{Ca}$, seguramente por no ver en ello ningún perjuicio. En efecto, en un texto del año 1969 (43) leemos que, entre las virtudes atribuidas a las adiciones de caliza, además de las ya citadas (corrección del color y disminución de los fenómenos de retracción), se enumera la consecución de una mayor docilidad en las pastas. Fenómeno éste, el de la docilidad, que se presta a numerosas lucubraciones.

Cuando los cementos para pavimentación se destinaban casi exclusivamente a la fabricación de mosaicos hidráulicos no había confusión posible, ya que los dichos cementos no eran, ni pretendían, ser verdaderos portland. El Dr. Calleja, en 1961, presentaba resultados de ensayos efectuados con dos cementos blancos, y, mientras que a uno de ellos, con 0,88 de pérdida al fuego, no le discutía su condición de portland en ninguno de los apartados, al otro, "para pavimentación" (pérdida al fuego 7,5 \%), lo encuadraba, apenas, en la categoría C-150, por sus bajas resistencias mecánicas y su elevada pérdida al fuego (4).

El problema surgió en la etapa del desarrollo económico caracterizada por un auge en la construcción de edificios de habitación y la necesidad que se impuso a los mosaístas de recurrir a sistemas que proporcionasen una mayor productividad con la consiguiente economía de mano de obra. Fue entonces cuando los mosailcos fueron progresivamente substituidos por los llamados "terrazos". Nos referimos, claro está, a las baldosas de terrazo, que equivalen a los "careaux granito" franceses, pero que no se pueden homologar con los terrazos americanos, fabricados in situ.

La inclusión de mármol troceado en piezas de dimensiones relativamente grandes, la fabricación en prensas automáticas y la exigencia de un rápido pulimento mecánico planteó a los fabricantes el probema de suministrar a los terracistas un aglomerante que, manteniendo todas las propiedades de los cementos para pavimentación, presentase unas altas resistencias iniciales análogas a las del cemento portland blanco 450. Quizá ello fue motivado por la larga tradición de mosaístas que tenían los terracistas y su poca capacidad de adaptación a nuevos materiales distintos de los hasta entonces usados.

Creemos que el problema fue planteado en sus líneas generales por una acertada exposición de Julián Rezola. "Los cementos portland obtenidos a base de mezcla exclusiva de clínker y yeso - nos dice- por norma general adolecen de tener poca plasticidad y bajo poder de retención de agua... Es lógico suponer que, si el cemento tiene estas características, automáticamente las mismas se transmitirán al hormigón, a no ser que se adopten las medidas necesarias, interviniendo en los áridos, y de una forma muy especial en las arenas, o se recurra a los aditivos. Para soslayar esto, y para evitar las dificultades que puedan presentarse a posteriori, el fabricante adiciona, en bajos porcentajes, calcitas o cal apagada" (28). 
En las prensas rotativas automáticas para terrazo el hormigón de cemento blanco va, generalmente, de la hormigonera a la prensa, por medio de una cinta transportadora inclinada. Es importante que la mezcla no presente señales de segregación durante el trayecto y que, al verterse sobre la placa de la baldosa, se distribuya uniformemente por ella, de modo que la pasta y los áridos mayores no sse separen. En realidad se trata de un problema, que podríamos llamar clásico, en la técnica de los hormigones, presentando, no obstante, las siguientes particularidades.

1) Se trata de un hormigón de una granulometría muy discontinua. En realidad, mejor sería considerarlo como una suspensión de áridos gruesos en el seno de un mortero de consistencia apropiada.

2) El mortero está compuesto por cemento blanco y arena. El primero, para cubrir sus objetivos de blancura y de alta resistencia inicial, suele ser de mayor finura que los portland corrientes y, por lo tanto, propenso a fraguado rápido y aún a fenómenos de falso fraguado.

3) La arenilla que entra en dicho mortero es, casi siempre, una arena de mármol preparada artificialmente. Su curva granulométrica varía bastante según las procedencias. Muchas arenillas contienen exceso de finos; otras, en cambio, son de poca finura y establecen una verdadera discontinuidad entre la arenilla y el cemento. Cuando dicha discontinuidad es muy acusada se pueden observar casos de segregación del árido grueso.

4) La relación agua/cemento, para una consistencia determinada, dependerá de la finura de los componentes del mortero. Una finura excesiva demanda mayor proporción de agua y reduce la resistencia inicial de las piezas fabricadas.

El problema es, de por sí, de gran complejidad, y tan sólo cuando el terracista sabe manejar todos los datos operando con ellos, como si de producir un hormigón normal se tratara, puede salirse airoso obteniendo excelentes resultados donde otros sólo cosecharon fracasos.

Pero el fabricante de cementos puede, y debe, auxiliar al terracista y lo consigue con la agregación de una pequeña cantidad de calcita, mármol o creta, al propio cemento, para que éste pueda adquirir una composición granulométrica que concuerde con la de las arenillas más comunes. Problema tan sólo en apariencia fácil de resolver, puesto que hay que tener muy en cuenta la concentración de cada componente —clínker, yeso, calcita- en cada fracción granulométrica del conjunto. No conviene ni que el yeso tenga mucha concentración en las fracciones con menos de $2 \mu$, ni que el clínker esté presente en fracciones por encima de 60-70 $\mu$. Es la calcita el material que debe establecer el enlace con la arenilla, con lo que se facilitará la docilidad, sin que se den perturbaciones de segregación.

Con lo dicho, queda implícitamente justificada la necesidad del fabricante para poder maniobrar, según las conveniencias del mercado, introduciendo en el cemento portland blanco un tercer componente. Sin embargo, como se demuestra por la simple inspección del cuadro que se adjunta, (tabla VIII), comparando las limitaciones del pliego RC-75 con las que se deducían de la "Propuesta de norma UNE para el cemento blanco", que vimos publicada en 1970 (36), vemos que cada vez se va restringiendo más el ámbito disponible.

El dilema planteado es bien simple, o ajustamos el cemento portland blanco a las condiciones del Pliego, o ajustamos los parámetros del Pliego de Condiciones a la adición (28).

De no hacerlo así, continuaremos con la interminable discusión de las muestras meteorizadas, puesto que "el total de materias inertes incorporadas (en su caso) al cemento puede ser $-\mathrm{y}$ tiene probabilidad de ser- menor que el total de materias inertes contenidas y halladas en el mismo" (5). 
Creemos que todavía hay posibilidad de que la Administración redacte y promulgue, como apéndice al Pliego RC-75, un Anexo menos rígido y más pragmático, que consienta: o bien con la entrada de determinados "cementos compuestos" en la categoría de los cementos portland, desde que cumplan con todas las demás condiciones - salvo la pérdida al fuego o el insoluble-, o bien que establezca para los cementos compuestos categorías superiores a la única (C-200) que aparece definida y especificada en el Pliego RC-75.

\section{CONCLUSION}

El concepto de que las adiciones al cemento de otros materiales, aparte del clínker y del yeso, no eran más que adulteraciones o fraudes, se vio superado por la evidencia de que, la mayor parte de las antedichas adiciones, no siendo nocivas, confieren a los cementos resultantes propiedades físico-químicas de gran interés para ciertas aplicaciones.

Sin embargo, resulta poco comprensible la discriminación que se hace entre adiciones activas y adiciones inertes, en primer lugar por la impropiedad de la palabra inerte ya que no existen agregaciones a los cementos totalmente desprovistas de actividad química. $\mathrm{y}$, en segundo lugar, porque, aun en el caso de que la actividad química de las adiciones fuera mínima, podrían proporcionar a las mezclas características físicas o mecánicas de mayor interés —en casos especiales- que las ampulosamente denominadas hidráulicas.

Tal discriminación está sancionada por los Pliegos de Condiciones, muy acusadamente en el RC-75, no sólo en la parte dispositiva, sino también en la parte prescriptiva, con la fijación de unos límites estrictos para el residuo insoluble y la pérdida al fuego. Para los cementos portland, los límites legales restringen casi del todo la posibilidad de incorporar a ciertas clases de cemento (citándose los de albañilería, para perforaciones profundas y blancos) las adiciones necesarias en la proporción conveniente para conferirles las propiedades que el mercado exige.

De paso, se citó el aspecto económico que presentan algunas adiciones, lo cual no es desdenable desde que, no siendo nocivas, signifiquen un aumento de la productividad de las instalaciones y una reducción de los consumos de energía, eléctrica y térmica, por tonelada de producto.

En último término se plantea el conocido dilema: o se adaptan los cementos especiales a los Pliegos de Condiciones o los Pliegos se adaptan a los cementos especiales que existen porque el mercado los pide, sin otras imposiciones que lo que se determine respecto al fraguado, inalterabilidad de volumen, resistencias mecánicas y a los agresivos y todo cuanto sea estrictamente necesario para garantizar la solidez y la durabilidad de las obras o prefabricados.

Para ilustración de lo expuesto damos las tablas VIII y IX, ésta última relativa a unos cementos especiales bien conocidos: los cementos blancos: 
TAв L A VIII

Prescripciones para los cementos blancos comparadas entre la "propuesta de norma UNE 41003 (11.67)" y el pliego de condiciones RC-75

\begin{tabular}{lcccccccc}
\hline Prescripciones & $\begin{array}{c}\text { CB-150 } \\
(\mathbf{U N E})\end{array}$ & $\begin{array}{c}\text { C-200-B } \\
(\text { RC-75) }\end{array}$ & $\begin{array}{c}\text { CPB-350 } \\
(\mathbf{U N E})\end{array}$ & $\begin{array}{c}\text { P-350-B } \\
(\text { RC-75) }\end{array}$ & $\begin{array}{c}\text { CPB-450 } \\
(\mathbf{U N E})\end{array}$ & $\begin{array}{c}\text { P-450-B } \\
(\text { RC-75) }\end{array}$ & $\begin{array}{c}\text { CPB-550 } \\
\text { (UNE) }\end{array}$ & $\begin{array}{c}\text { P-550-B } \\
\text { (RC-75) }\end{array}$ \\
\hline $\mathrm{MgO}$ & - & - & 5 & 5 & 5 & 5 & 5 & 5 \\
$\mathrm{SO}_{3}$ & - & 3,5 & 4 & 4 & 4 & 4,5 & 4 & 4,5 \\
$\mathrm{P} . \mathrm{F}$. & 19 & - & 8 & 4 & 6 & 3,5 & 4 & 3,5 \\
Residuo insoluble & 5 & - & 3 & 3 & 3 & 2,5 & 1 & 2,5 \\
Materia inerte & - & 35 & - & - & - & - & - & - \\
Densidad real & 2,7 & - & 2,8 & - & 2,8 & - & 3,0 & -
\end{tabular}

Cálculo de la adición (\%)

$\begin{array}{lrrrrrrrl}\text { Humedad media } & 0,5 & 0,5 & 0,5 & 0,5 & 0,5 & 0,5 & 0,5 & 0,5 \\ \mathrm{H}_{2} \mathrm{O} \text { del yeso } & 1,8 & 1,6 & 1,8 & 1,8 & 1,8 & 2,0 & 1,8 & 2,0 \\ \mathrm{H}_{2} \mathrm{O} \text { total } & 2,3 & 2,1 & 2,3 & 2,3 & 2,3 & 2,5 & 2,3 & 2,5 \\ \mathrm{P} . \mathrm{F} . \quad-\mathrm{H}_{2} \mathrm{O} & 16,7 & 15,4 & 5,7 & 1,7 & 3,7 & 1,0 & 1,7 & 0,0 \\ \mathrm{CO}_{3} \mathrm{Ca} \text { equivalente } & 38 & 35 & 13 & 4 & 8 & 2 & 4 & 0 \\ \text { Residuo insoluble } & 5 & - & 3 & 3 & 3 & 2,5 & 1 & 2,5 \\ \text { Suma (adición) } & 43 & 35 & 16 & 7 & 11 & 4,5 & 5 & 2,5\end{array}$

Fraguado

PRINCIPIO

después de

30 min. $\quad 45$ min. $\quad 30 \mathrm{~min} \quad 45 \mathrm{~min} . \quad 30 \mathrm{~min} . \quad 45 \mathrm{~min} . \quad 30 \mathrm{~min} . \quad 45 \mathrm{~min}$.

FINAL

antes de

$12 \mathrm{~h}$

$12 \mathrm{~h}$

$12 \mathrm{~h}$

$12 h$

$12 h$

$12 \mathrm{~h}$

$12 \mathrm{~h}$

$12 \mathrm{~h}$

Expansión

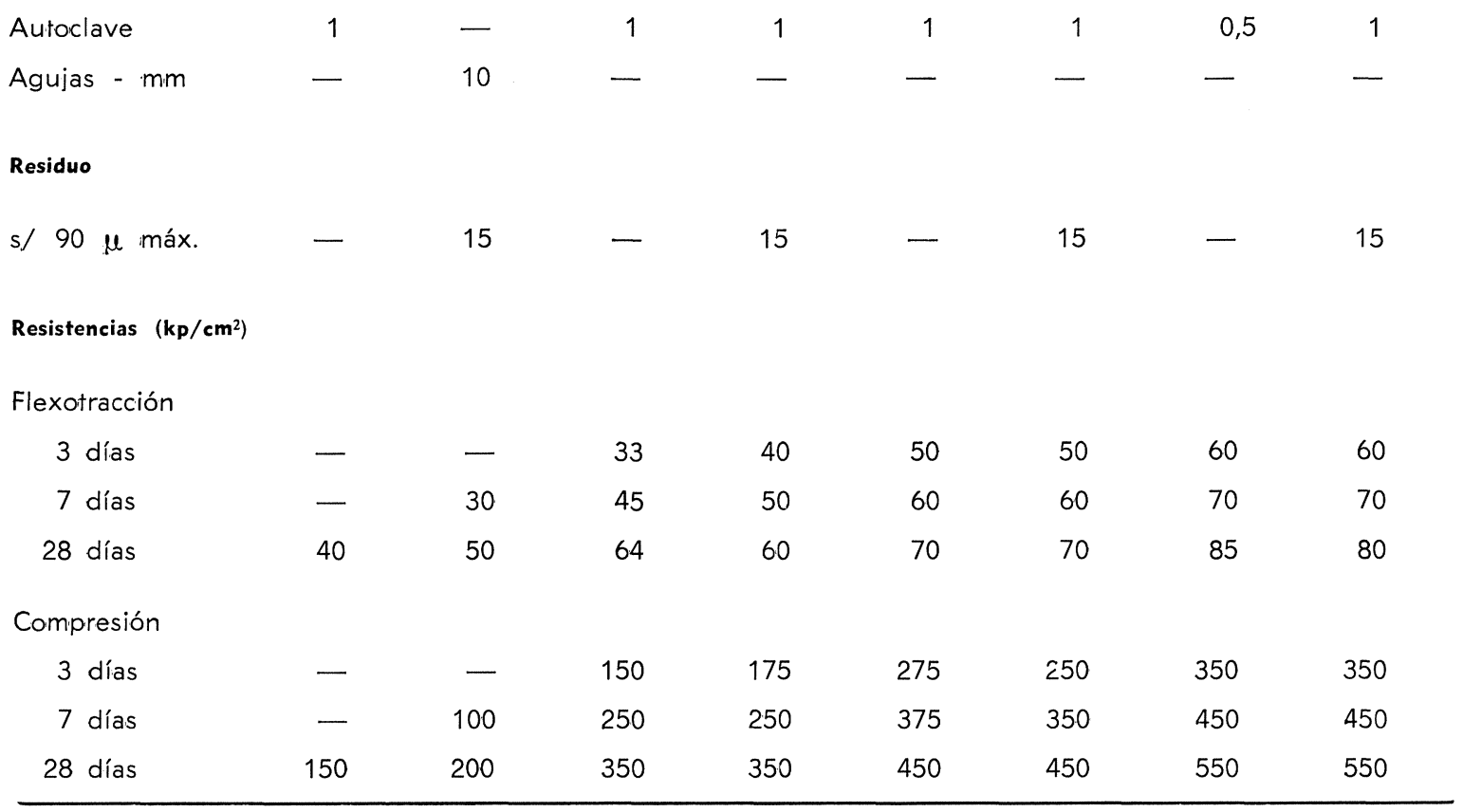


TAB L A IX

Resultados de los análisis de muestras de cementos portland blancos españoles

\begin{tabular}{|c|c|c|c|c|c|}
\hline Variables & $\mathbf{A}$ & B & c & D & $\mathbf{E}$ \\
\hline $\mathrm{MgO}$ & 0,49 & 0,42 & 0,62 & 0,28 & 0,82 \\
\hline $\mathrm{SO}_{3}$ & 1,35 & 2,55 & 1,89 & 2,79 & 1,55 \\
\hline Residuo insoluble & 0,28 & 0,32 & 0,20 & 0,22 & 0,30 \\
\hline Pérdida al fuego & 3,86 & 4,84 & 5,13 & 6,04 & 7,80 \\
\hline Densidad real & 3,080 & 3,033 & 3,030 & 3,042 & 3,028 \\
\hline \multicolumn{6}{|l|}{ Fraguado } \\
\hline Principio & $2 \mathrm{~h} 28 \mathrm{~min}$ & $1 \mathrm{~h} 40 \mathrm{~min}$ & $1 \mathrm{~h} 30 \mathrm{~min}$ & $3 \mathrm{~h} 43 \mathrm{~min}$ & $2 \mathrm{~h} 15 \mathrm{~min}$ \\
\hline Final & $3 \mathrm{~h} 18 \mathrm{~min}$ & $3 \mathrm{~h} 10 \mathrm{~min}$ & $2 \mathrm{~h} 50 \mathrm{~min}$ & $6 \mathrm{~h} 20 \mathrm{~min}$ & $3 \mathrm{~h} 5 \mathrm{~min}$ \\
\hline \multicolumn{6}{|l|}{ Expansión } \\
\hline Agujas: $\mathrm{mm}$ & 1 & 0,5 & 0,5 & 0,5 & 1 \\
\hline \multicolumn{6}{|l|}{ Residuo } \\
\hline s/ $90 \mu$ & 1,8 & 0,6 & 0,9 & 1,9 & 0,6 \\
\hline Superficie BLAINE & 3.999 & 4.348 & 4.420 & 3.719 & 4.512 \\
\hline \multicolumn{6}{|l|}{ Resistencias ( $\left(\mathbf{k p} / \mathbf{c m}^{2}\right)$} \\
\hline \multicolumn{6}{|l|}{ Flexotracción } \\
\hline 3 días & 48 & 57 & 55 & 50 & 53 \\
\hline 7 días & 72 & 74 & 76 & 60 & 66 \\
\hline 28 días & 80 & 88 & 88 & 76 & 84 \\
\hline \multicolumn{6}{|l|}{ Compresión } \\
\hline 3 días & 290 & 302 & 280 & 252 & 278 \\
\hline 7 días & 400 & 396 & 362 & 310 & 354 \\
\hline 28 días & 562 & 548 & 495 & 456 & 470 \\
\hline \multicolumn{6}{|l|}{ Reflectancia direcional } \\
\hline Filtro ámbar & 85,0 & 83,8 & 82,3 & 82,3 & 80,2 \\
\hline Filtro verde & 84,8 & 83,2 & 82,0 & 81,5 & 79,7 \\
\hline Filltro azul & 80,0 & 77,2 & 76,5 & 73,3 & 72,5 \\
\hline
\end{tabular}

\section{B I B $\quad \mathbf{L}$ I 0 O G}

(1) Anonimo: "Le Brique Silice-Calcaire". "Revue des Matériaux de Construction" n.o 301 (oct. 1934), p. 292.

(2) Birthelmer, J.: “Gemeinsame oder getreunte Vermahlung”, Silikattechnik, 6-76-77 (1965), citado en "Symposium de Tokio" (1968), IV, p. 179.

(3) Blount, B.: "Cemento", Calpe, Madrid (1923), p. 113. 
(4) Calleja, J.: "Los cementos españoles ante la propuesta de un nuevo Pliego General de Condiciones", Ultimos Avances en Materiales de Construcción, n. ${ }^{\circ} 101$ (1961).

(5) Calleja, J.: "En torno al Pliego RC-75”, Cemento-Hormigón, n..$^{\circ}$ 504, (febrero 1976 ), p. 105.

(6) Candlot, E.: “Ciments et Chaux Hydrauliques”, Baudray et Cie. París (1891), p. 90.

(7) Capella, F.: “Agregaciones a los cementos blancos”, Afinidad, 3. " Epoca, 93-94 (1950), p. 506.

(8) Cembureau Papers: "Review of Standards for Cements other than Portland" (1958), p. 11-127-137-158.

(9) ChatterJi, S. K.: "Mechanisms of Sulphate Expansion of Hardened Cement Pastes", Simposio de Tokio (1968), III, p. 338.

(10) Chassevent, L.: “Compte Rendu” (1934), 199, 673.

(11) FARran, J. y Maso, J. C.: “De l'emploi des substitutions calcaires pour l'améloration des agregats à bétons”, Rev. des Matériaux, n. 586 (1964) p. 195.

(12) Hadley, D. W.: “P. C. A. Bull.”, 139 (1961), citado por KEIL, F. en “Cemento” Edit. Tec. Asoc.”, Earcelona (1973), p. 186.

(13) Jander, W. y Franke, B.: Z. anorg. allgem. Chem. (1941) 247, 161., citado por LAfuma, H. en "Chimie Appliquee aux Matériaux de Construction".

(14) KaIsER, H: . Symposium Tokio (1968), IV, p. 275.

(15) KEIL, F.: “Cemento”, Edit. Tec. Asoc., Barcelona (1973), p. 32, 33 y 35.

(16) KLeINLOBEL, A. L.: "El cemento Portland y sus aplicaciones”, Edit. Ossó Barcelona (s.a.), p. 27.

(17) LEA, F. M.: “Química del Cemento y del Hormigón”, Edic. revisada, Madrid, (1960), p. 40.

(18) id. Op. cit., p. 429.

(19) id. Op. cit., p. 543.

(20) id. Op. cit., p. 548.

(21) Lea, F. M. y Deech, C. H.: “Química del Cemento y del Hormigón”, Manuel Marín, edit. Barcelona (1941), p. 358.

(22) Meade, R. K.: "Portland Cements, 2.a edic. The Chemical Publishing Co. Easton, Pa (1911), p. 381.

(23) Michaelis, W.: Memoria leída ante la Asociación Alemana de Fabricantes de Cemento (1909), Berlín, citado por LEA (1960), p. 40.

(24) Palomar Collado, P.: “Aglomerados de Hormigón Hidráulico”, Bosch, edit. Barcelona, I, p. 82.

(25) P. LI. P.: “Cemento blanco a base de escorias", Cemento-Hormigón, n.o 276, (1967) marzo, p. 114.

(26) Perry, J. H.: "Manual de Ingeniero Químico”, México (1959), II, p. 1734.

(27) R. C. 75 : "Pliego de Prescripciones Técnicas Generales para la Recepción de Cementos", B. O. E., núms. 206 y 207, de 28 y 29 de agosto (1975), arts. 1, 7, 1 - 1, 7, 2 y 2, 6.

(28) Rezola, J.: "Precisiones sobre el cemento blanco", Desarrollo-Suplemento, (1975), enero, 19, p. XXVII.

(29) Rimathe, W.: "El Cemento Portland Blanco", Utlimos Avances en Mat. de Const. (1959), nov. dic., núm. 96.

(30) Rookwood, N.: “Pulverized Calcite merely a cement adulterant?", Rock Products (1958), julio, p. 21.

(31) Spohn, E. y LIEBeR, W.: "Reactionen zwischen calciumcarbonat und Portlandzement. Beitrage au dan System $\mathrm{C}_{3} \mathrm{~A}-\mathrm{CaCO}_{3}-\mathrm{H}_{2} \mathrm{O}$ und $\mathrm{C}_{4} \mathrm{AF}-\mathrm{CaCO}_{3}-\mathrm{H}_{2} \mathrm{O}$ ", Zement-Kalk-Gips, sep. (1965), pp. 483-5.

(32) Stutterheim, N.: "Portland Blast-Furnace Cements. A Case for Separate Grinding of Slag", Symposium de Tokio (1968), IV, p. 271.

(33) TAYloR, H. F. W.: “The Chemistry of Cements" Academic Press, Londres-New York (1964), p. 230, nota 87.

(34) id. Op. Cit. I, p. 9.

(35) id. Op. Cit. I, p. 169, fig. 1.

(36) UNE 41 003: “Propuesta de norma UNE para el cemento blanco". Cemento-Hormigón (1970), agosto, p. 783-84.

(37) Varios Autores: "Los áridos en la construcción”, Edit. Tec. Asoc., Barcelona (1967), p. 301 y ss.

(38) Vis, G.: “A propos de l'altération des bétons", Révue des Matériaux de Construction, n. $478-479$ (1955), p. 205.

(39) Virella, A.: “O Cimento Portland”. Congresso Internacional do Cimento. Lisboa (1960), II, p. 326.

(40) Virella, A.: “Cementos especiales para perforaciones petrolíferas”. Cemento-Hormigón, n. 310 (1960), p. $8-10$.

(41) Id. "El Profesor Fabio Ferrari", Cemento-Hormigón, n.o 464 (1972), p. 961.

(42) Id. "Evolución del problema de la molienda. Tercera Parte”, Cemento-Hormigón, n. 381 (1965), p. 767.

(43) Id. "El color de los Cementos", Cemento-Hormigón, n. 423 (1969), pp. 617 y ss.

(44) Id. "El Pliego de 1975”, Cemento-Hormigón, octubre (1975), n. * 499, p. 1.006.

(45) Vizcaino y Cucarella, I.: "El Cemento Portland Artificial”, Imp. Alemana, Madrid (1906), p. 6.

(46) WAdiA, D. A.: “Grinding gypsum separate from clinker”, Rock Products, (1962), mayo, p. 85. 